\title{
Food-pellet size modifies the hoarding behavior of foraging rats
}

\author{
IAN Q. WHISHAW and JO-ANNE TOMIE \\ University of Lethbridge, Lethbridge, Alberta, Canada
}

\begin{abstract}
Rats were allowed to forage for different-sized (20- to 500-mg) food pellets from a cage attached to a straight alley or from a cage placed in the center of an 8-arm radial maze. In both tasks, food-pellet size influenced motor responses. Small food pellets were swallowed at the food source. Medium-sized food pellets were grasped by mouth, and, after the rat stepped away from (dodged) the food source, they were eaten as the rat adopted a sitting posture. Large food pellets were hoarded to the adjacent enclosure. The food-related motor patterns prevailed despite changes in the distance to the food source, despite changes in the rats' deprivation level, and after visual occlusion. If hoarding was frustrated by blocking the home cage entrance, dodging angle and distance were still proportional to food-pellet size. Food size did not, however, influence selection of arms on an 8-arm maze with arms consistently associated with food pellets of given size. The novel contribution of this study is the demonstration that stimulus features associated with food size influence motor behavior, including the complex motor sequence involved in hoarding food. This paradigm not only provides new information about factors that influence hoarding in the rat, but also should prove useful for the study of food-related motor behavior of the rat and its neural control.
\end{abstract}

Hoarding has been operationally defined as the transportation of objects, particularly food, from a source to a secluded area (Ross, Smith, \& Woessner, 1955). On the basis of his studies on wild rats in a seminatural environment, Calhoun (1962) observed that rats engaged in at least two types of hoarding: larder and scatter hoarding. Female rats transported food from a central depot to their nests after the birth of a litter and continued hoarding until the pups were about 60 days old, at which time they were able to forage for themselves. The larder no doubt facilitated the pups' weaning. In addition, all the rats transported food away from the depot, usually to nearby shelters (see also Lore \& Flannelly, 1978; Pisano \& Storer, 1948; Southern, Watson, \& Chitty, 1946; Takahashi \& Lore, 1980; Thompson, 1948). Once a cache was formed in this way, it was treated as a secondary depot from which food was transported to still other harborages. This scatter-hoarding behavior apparently served to distribute food resources throughout the colony's territory.

Hoarding has also been observed in domesticated laboratory rats (Wolfe, 1939). An extensive literature has been directed toward identifying the factors that influence its occurrence (for reviews, see Marx, 1950; Munn, 1950; Ross et al., 1955). Rats will hoard food (Morgan, Stellar, \& Johnson, 1943; Stellar \& Morgan, 1943), water, in the form of water soaked cotton, (Bindra, 1947), nest-

This research was supported by a grant from the Natural Sciences and Engineering Research Council of Canada. Requests for reprints should be sent to Ian Q. Whishaw, Department of Psychology, University of Lethbridge, Lethbridge, Alberta T1K 3M4, Canada. ing material (Calhoun, 1962), and junk items (McCain, Garrett, Reed, Mead, \& Kuenstler, 1964; Ross, Smith, \& Nienstedt, 1950; Wallace, 1978, 1985); they even attempt to hoard body parts, such as a paw or tail (Licklider \& Licklider, 1950; Wallace, 1974). Hoarding is influenced by previous deprivation (Morgan et al., 1943; Porter, Webster, \& Licklider, 1950; Stellar \& Morgan, 1943), body weight (Fantino \& Cabanac, 1980; McCleary \& Morgan, 1946), hormonal status (Herberg, Pye, \& Blundell, 1972), temperature (Fantino \& Cabanac, 1984), previous experience or an item's partibility and novelty (Wallace, 1979), group size (Miller \& Postman, 1946), and exposure of the food source relative to surrounding areas of shelter (Bindra, 1948a; Miller \& Viek, 1944; Viek \& Miller, 1944).

In the present study, we examine the influence that the size of food pellets has on hoarding behavior. The experiments were conducted with two foraging conditions. In the first condition, rats were allowed to obtain food pellets of different sizes from the end of a straight alley attached to their home cage. Measures were made of hoarding behavior as a function of food size. The effects of deprivation, visual occlusion, and traveling distance were also evaluated, to assess the strength of association between food size and hoarding. In a second condition, the rats were allowed to forage for food pellets of different sizes located at the end of the arms of a radial 8-arm maze. The objective of the condition with the straight alley was to determine how robust the influence of food size is on hoarding tendencies. The objective of the second condition was to determine if rats showed a preference for food items that they would hoard, as opposed to those they would not hoard. 


\section{METHOD}

\section{Subjects}

The main experiment reported here involved the use of four adult female Long-Evans derived rats (University of Lethbridge animal vivarium). They were approximately 150 days old, weighed between 190 and $230 \mathrm{~g}$ when the experiment began, and were housed together in a large wire mesh hanging cage. Additional observations were made on 54 ( 12 female and 42 male) rats varying in age from 16 to 300 days. The colony room was on a normal 12:12-h light:dark (lights on from 8:00 am-8:00 pm) cycle, and testing was done between 1:00 and 4:00 pm of the light cycle. Two weeks prior to the beginning of the experiment, the rats were placed on a fooddeprivation schedule, which held them between $80 \%$ and $85 \%$ of their initial body weight.

\section{Apparatus}

The tests were conducted using a Plexiglas alley or an 8-arm radial maze.

Straight alley. The alley was made of clear Plexiglas. It was $106 \mathrm{~cm}$ long, $25 \mathrm{~cm}$ wide, and $26 \mathrm{~cm}$ high. With the addition of a second section, it could be expanded to a length of $227 \mathrm{~cm}$. A wire mesh cage $21 \mathrm{~cm}$ wide, $25 \mathrm{~cm}$ high, and $19 \mathrm{~cm}$ long, with a metal roof, similar to the rat's home cage, was located at one end of the alley. A door on the mesh cage controlled access to the alley. At the other end of the alley a hole $4 \mathrm{~cm}$ in diameter was cut into the Plexiglas, through which food could be manually presented.

Eight-arm maze. The symmetrical 8-arm maze featured 60 -cm arms $(9 \mathrm{~cm}$ wide, bordered by $2.5-\mathrm{cm}$ walls on either side) attached to a circular platform $38 \mathrm{~cm}$ in diameter. The platform was covered by an enclosure $12 \mathrm{~cm}$ high that contained openings to each alley $9 \mathrm{~cm}$ square. A rat could be placed into the central housing area through a door in its roof. The assembly was mounted $95 \mathrm{~cm}$ above the floor, in a small room where all distal visual cues were kept constant.

\section{Food}

Eight different-sized food pellets (BioServe Inc., P.O. Box 450, Frenchtown, New Jersey) weighing 20, 37, 45, 75, 94, 190, 300, and $500 \mathrm{mg}$ were used (see Figure 1). Hereafter, the pellets are referred to as Sizes 1 to 8.

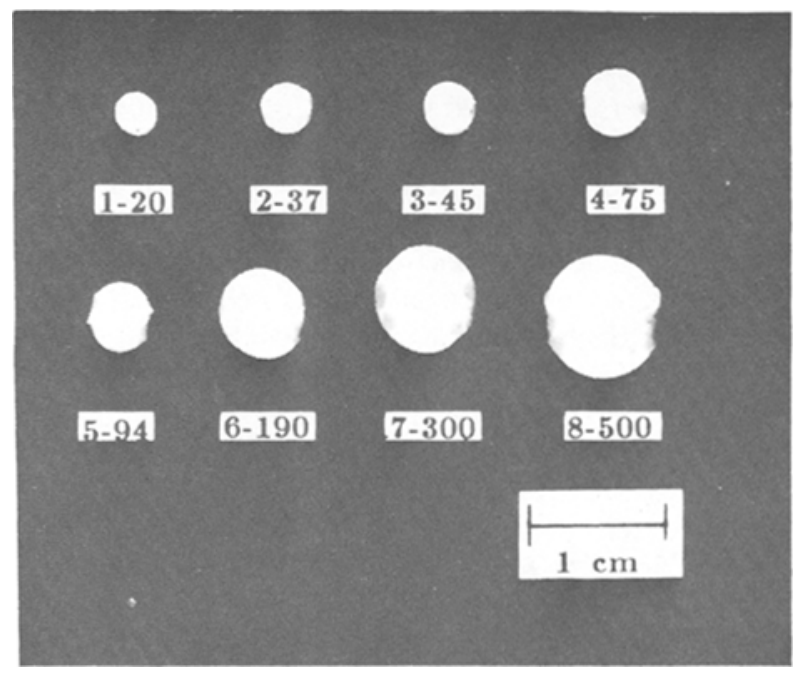

Figure 1. Photograph of food pellets, showing their relative sizes. Weight is given in grams, after pellet number.

\section{Movements}

In many of the tests, the behavior of the rats on obtaining a food pellet was designated with the terms eat, sit, or hoard. If a rat accepted a food pellet and ate it without turning laterally away or moving backward from the food source, the behavior was given the designation eat. In these cases, the rats usually chewed and swallowed the food after picking it up with their mouths, but occasionally they transferred the food to their paws and then ate it. If a rat grasped a food pellet and then turned away from the food source, or stepped backward with the food, and then sat on its haunches to eat the food, the behavior was given the classification sit. Invariably, the rats transferred the food from their mouths to their paws when they adopted a sitting posture, and they ate the food from their forepaws. If a rat took the food pellet in its mouth and transported it to the covered portion of the test area, the behavior was classified as a hoard. Sometimes they ate the food after transporting it, but often they left it and returned for another pellet.

\section{Filming}

A Sony Betamax recorder (Beta III mode) was used to videotape the rats' behavior, and the tapes were analyzed by using the frameby-frame (30 frames/sec) playback feature of the recorder (see Whishaw \& Tomie, 1987).

\section{Eye Patches}

To occlude vision, the hair around the rats' eyes was shaved and the eyes were taped shut with small pieces of black electrician's tape. The tape was easy to apply or remove for the relevant tests; after a few practice applications of the tape, the rats did not attempt to remove it themselves.

\section{Procedure}

Straight-alley hoarding tests. Before the formal testing began, the rats were adapted to the straight alley and the food-administration procedure. They were placed in the cage, and, when they traveled to the end of the alley, they were given food pellets of different sizes. Each rat was allowed to retrieve about 20 food pellets on each daily session. The adaption procedure lasted for 7 days, by which time all of the rats ran readily to the end of the alley for food. Their responses over the training period were recorded.

Once a stable baseline of performance in the straight alley was established, the following tests were given.

1. Effects of eye occlusion: The rats were given four days of testing in the 106-cm alley. On the first 2 days, their eyes were open; on the second 2 days, their eyes were occluded with patches. On each test day, each rat received 40 food pellets ( 5 pellets of each of the eight sizes) randomly presented 1 at a time. The food was delivered manually when the rat inserted its snout into the aperture at the end of the alley. The rat's behavior upon receiving a pellet was classified as eat, sit, or hoard.

2. Effect of deprivation: In the $106-\mathrm{cm}$ alley, the rats were given 5 days of testing while on the food deprivation schedule, and 5 days of testing after having had ad-lib access to food in their home cage. On each day, the rats were given 40 trials (5 pellets of each of the eight sizes, selected randomly). Their behavior was classified as hoarding or not hoarding.

3. Effect of distance: The rats were given 5 days of testing in the 106-cm alley, and 5 days of testing in the $227-\mathrm{cm}$ alley. On each day, the rats received $\mathbf{4 0}$ trials as administered in the deprivation test. Their behavior was classified as either hoarding or not hoarding.

4. Straight-alley nonhoarding test: For this test, the cage at the end of the alley was blocked off so that the rat was unable to hoard food in it. The rat was then placed directly into the alley. Food pellets were presented through the hole at the end of the alley. Each rat was tested for 5 days, with eight trials (one for each pellet size) given on each day. Measures were made of (1) the distance that 
the rat's nose moved directly back from the wall containing the hole, and (2) the angle between the rat's position when it took the food and its position when it sat and ate the food.

Eight-arm-maze hoarding tests. Each arm of the maze was baited with food pellets of one size, so that both the arm and the food-pellet size had a constant relation to ambient room cues. The amounts of food in each arm were made approximately equal by means of the following equations of number and food-pellet size: $1=15,2=8,3=6,4=4,5=3,6=2,7=1,8=1$. This gave about $300 \mathrm{mg}$ of food in each arm apart from the arm with the Size 8 pellet, so that if there was a preference for large food pellets that could be hoarded, the rats should have favored the arm containing the Size 8 pellets.

1. Acquisition, eyes open: For the acquisition test, each arm was baited with the appropriate number of food pellets, and a rat was placed in the central housing area through a door in its roof. The rat was allowed to retrieve food from each alley on each of 7 successive days. The following measures were recorded daily: (1) If a rat reentered an arm sufficiently far to search for the food in the food cup, the reentry was called an error. (2) The order in which the rat entered the arms was recorded, so that any preference for an arm or sequence of arms could be determined. (3) The eat, sit, and hoard designations were used to record the behavior of the rat upon food retrieval.

2. Reacquisition, eyes patched: The reacquisition test was administered in the same way as the acquisition test, except that the eyes of the rats were patched. The reacquisition test began on the day after the end of the acquisition test.

\section{RESULTS}

From the outset, we observed a robust relation between food-pellet size and the behaviors of all the rats studied. The behavioral patterns are illustrated in Figure 2. When the rats emerged from their cage, they walked or trotted down the alley to the food source (Figure 2A and B). The rats ate small food pellets directly (Figure $2 \mathrm{C}$ ); they sat back on their haunches with the medium-sized food pellets, which they ate from their paws (Figure 2D); and they trotted or galloped back to the cage with the large pellets (Figure 2E). This relation between food size and behavior, which was observed in every rat, appeared on first encounters with the food. Three of the youngest rats studied displayed this pattern of behavior at 17 days of age, on their first encounter with the food in the straight alley. A numerical summary of the responses, of the four rats used in the remaining tests in this report, to food pellets of different sizes is shown in Figure 3 (top).

\section{Visual Occlusion}

Behavior in relation to food-pellet size was identical in rats tested in the eyes open and occluded conditions (Figure 3). An analysis of variance on the relation of behavior, vision, and food size gave no significant main effects. There were significant interactions of food size $X$ behavior $[F(14,42)=18.2, p<.001]$ and vision $\times$ behavior $[F(14,42)=18.2, p<.005]$, and a significant three-way interaction of vision, food size, and behavior $[F(14,42)=3.29, p=.0014]$. As shown in Figure 3, these interactions were due to (1) the relatively fixed relation between food size and the tendency to eat, sit, or hoard food, and (2) increases in the probability that the

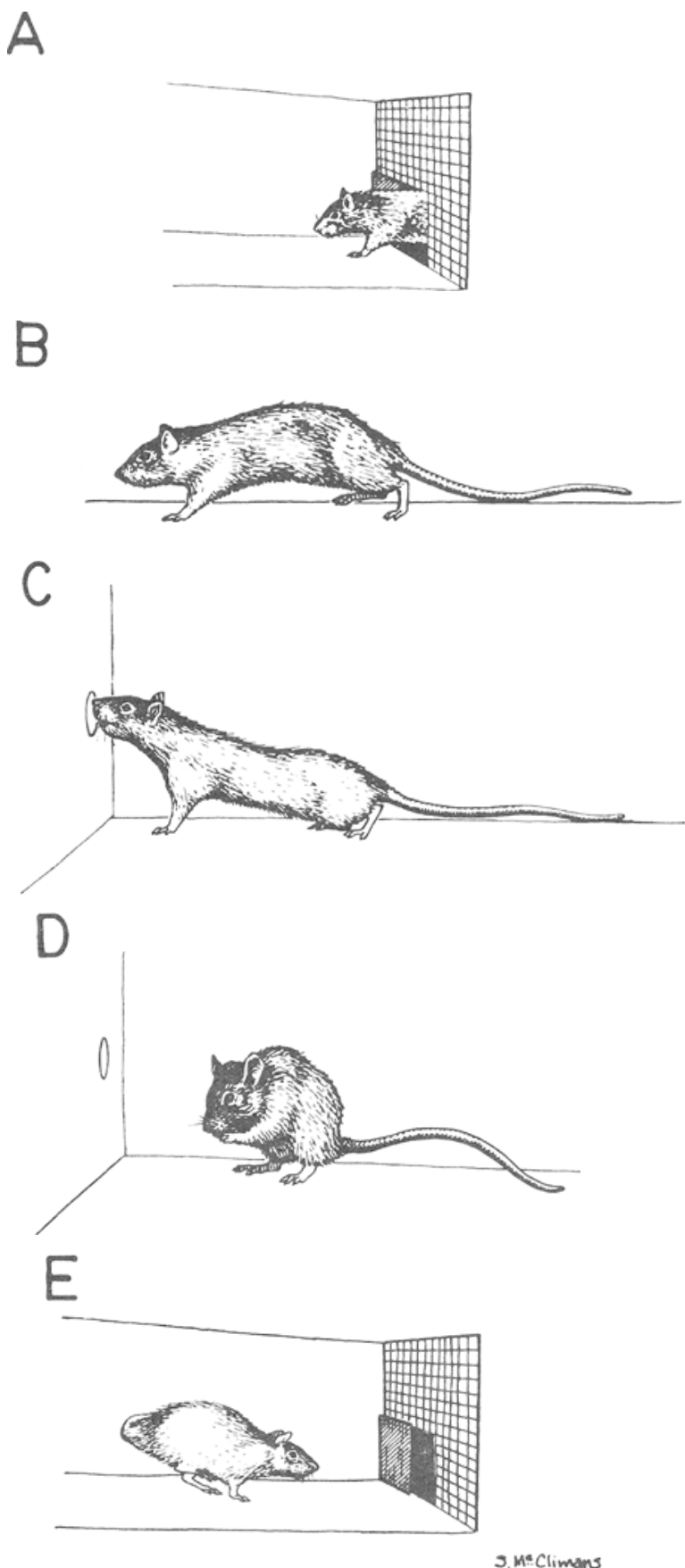

Figure 2. Typical motor behavior observed in a straight-alley hoarding task. A, exit from cage; B, trot to food source; C, standing posture adopted when eating a small food pellet at food source; D, sitting posture adopted for eating medium-sized food pellets; $E$, gallop to the home cage with a large food pellet.

rats would sit and consume the medium-sized pellets when their eyes were occluded.

\section{Distance}

Varying the distance between the home cage and food source did not significantly effect the pattern of behavior toward food pellets of different sizes. Figure 4 (top) il- 

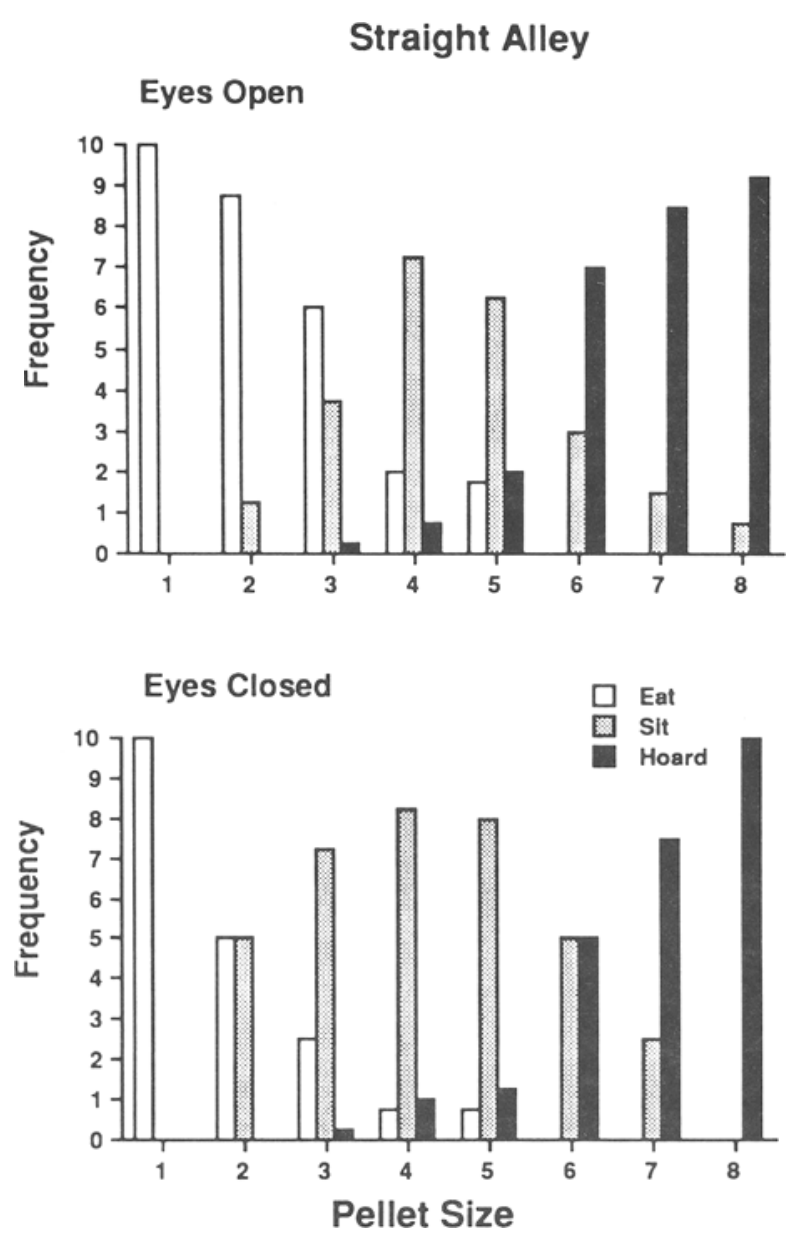

Figure 3. Effect of food size on behavior. "Eat" = food eaten while standing; "sit" = food eaten after rat adopted a sitting posture; "hoard" = food transported to the home cage. In the eyes-closed test, vision was prevented by placing a small black patch over each eye. Note that small pellets were eaten while rats were standing, medium-sized pellets were eaten while rats were sitting, and large pellets were hoarded.

lustrates the relation between food-pellet size and hoarding distances of $106 \mathrm{~cm}$ and $227 \mathrm{~cm}$. There was no significant effect of distance, and no significant interaction between distance and food-pellet size, but the rats were much more likely to hoard the large pellets, giving a significant effect of pellet size $[F(7,21)=77.9, p<.001]$.

\section{Deprivation}

Varying the deprivation between $24 \mathrm{~h}$ of food deprivation and satiation did not significantly affect the pattern of behavior toward food pellets of different sizes (Figure 4, bottom). Varying the deprivation produced a pronounced change in latency to hoard, but it did not change the rats' selection of pellets to hoard. When deprived, the rats approached the food quickly, but when they were satiated, there were long delays between consecutive approaches. Nevertheless, the effect of deprivation condition was not significant, nor was the interaction between food-pellet size and deprivation. There was, however, a significant effect of pellet size $[F(7,21)=138$, $p<.001]$.

\section{Straight-Alley Nonhoarding Test}

When placed into the alley, the rats explored the alley and the blocked entrance to the cage. When they were subsequently given food, none attempted to hoard to the obstructed cage. Nevertheless, their behavior with respect to food pellets of different sizes was still size-dependent. Typical examples of behavior are shown in the illustrations in Figure 5. The rats ate Size 1 pellets without grasping them with their forepaws and without turning away from the food aperture (one rat refused Size 1 pellets on most trials). Size 2 pellets were also eaten at the hole, although they were often grasped with the forepaws first and then with the mouth. Larger food pellets were usually grasped in the mouth, after which the rats turned and moved away from the aperture before transferring the food to their paws in order to sit back on their haunches and

\section{Effect of Distance}
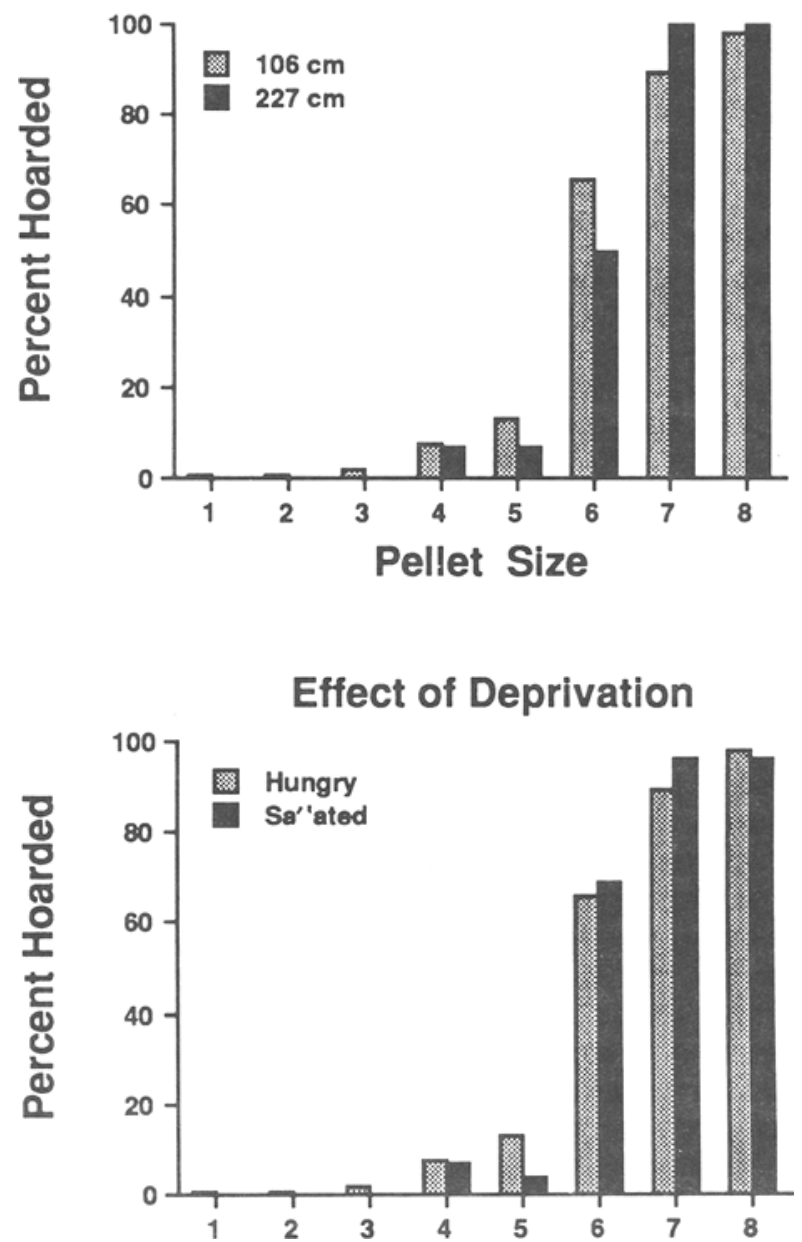

Figure 4. Effect of distance and food deprivation on the probability of hoarding food pellets of different sizes. Distance between food source and home cage was either $106 \mathrm{~cm}$ or $227 \mathrm{~cm}$, and deprivation was either $0 \mathrm{~h}$ or $24 \mathrm{~h}$. 
eat. The rats often turned completely around with the largest food pellets and stepped away from the food hole (Figure 5, Frame 8). The distance moved and angle turned between taking the pellet and sitting and eating it was measured on 10 trials per food pellet per rat. The relation between food size and both distance and angle was almost linear (Figure 6). The distance moved in- creased significantly as pellet size increased $[F(7,21)=$ $19.96, p<.001]$, as did the angle turned $[F(7,21)=$ $14.42, p<.001]$.

\section{Eight-Arm-Maze Hoarding Tests}

The rats quickly learned to enter the arms of the radial maze, and by the 7th day of testing, their performance

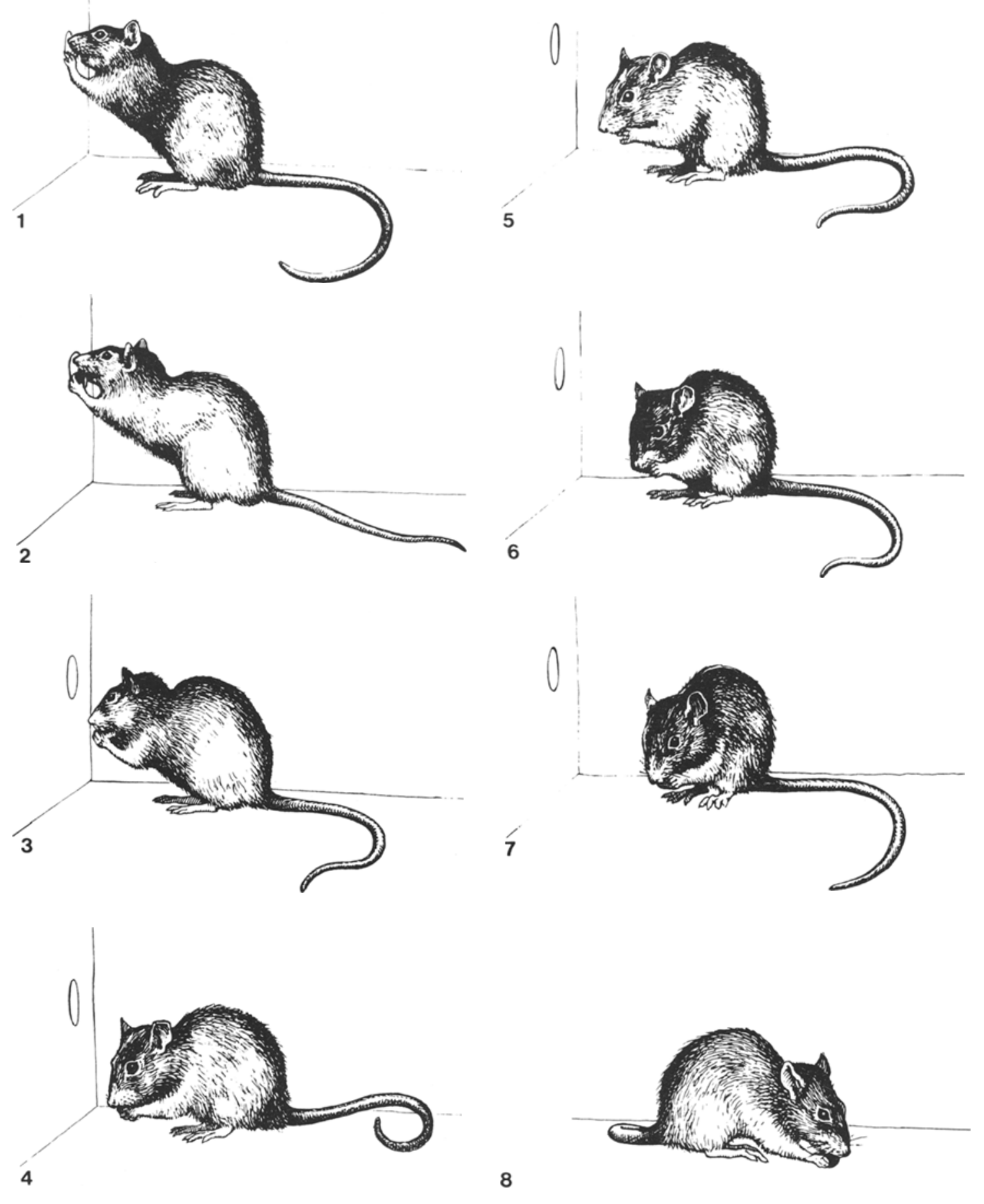

Figure 5. Effect of food-pellet size on movement in an enclosure that did not permit hoarding. Food pellets were presented manually at the circular opening. Numbers refer to food-pellet size. Note that as food-pellet size increases, the rat turns further away from the food source. 


\section{Distance}
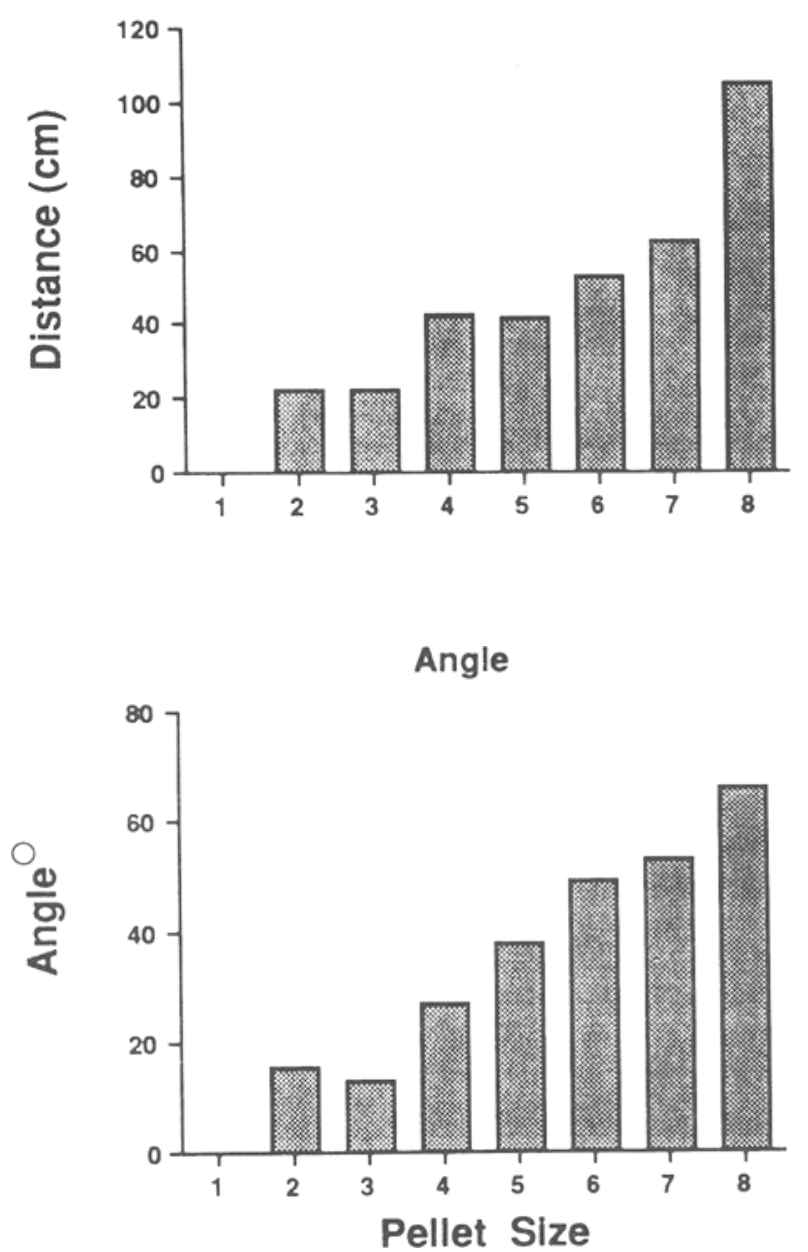

Figure 6. Effect of food-pellet size on movement at a food source. Note that as pellet size increases, the distance and angle that the rat turns from the food source increases.

had improved until they visited each arm without reentering an arm. Patching their eyes disrupted their performance, but again they showed improvement over the subsequent days of testing. Thus, there were significant changes in their performance during the eyes-open $[F(3,18)=9.77, p<.05]$ and eyes-occluded $[F(3,18)$ $=7.42, p<.05]$ conditions. The results are summarized in Figure 7 (top).

Since each alley was associated with food pellets of a given size, the order of alley selection was analyzed in order to determine whether food size influenced alley choice. The analysis was carried out with Page's $L$-trend test, which is an extension of the Friedman two-way analysis of variance by ranks (Cohen \& Holliday, 1982). The analysis was done separately for each day of training, as well as on the mean performance. None of the analyses approached significance ( $p$ s ranged from .25 to .79). Additional analyses were done to determine if there were correlations in the performance of individual rats over days. Of all possible (eyes-open or -occluded) correla- tions for each rat, only two were significant, a result that does not differ from chance. To estimate possible daily changes in preference, each day's performance was correlated with an ideal selection strategy (making choices for arms containing Sizes 8 to 1 , sequentially). The results are summarized in the lower portion of Figure 7 . There were no significant correlations, nor was there any tendency for consistent patterns of selection to develop over days of testing.

The motor behavior of the rats upon retrieving the food pellets was analyzed with respect to whether food was eaten while standing at the dish (eat), eaten in a sitting posture (sit), or hoarded (hoard). In both conditions, the rats showed a preference for eating the small food pellets while standing, and a preference for hoarding the large pellets. Generally, the rats approached the food wells on
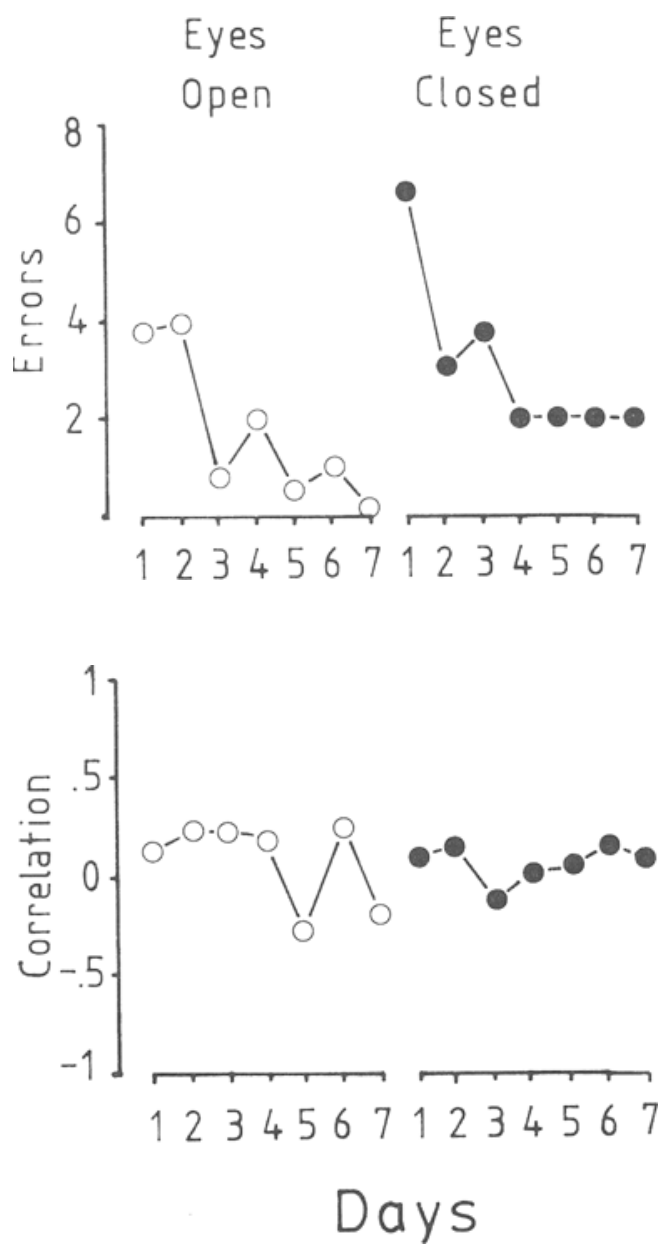

Figure 7. Top: errors (reentries) on the 8-arm maze test under the sighted and occluded conditions. Each arm was associated with pellets of one size, but the number of pellets in each arm was adjusted so that the amounts of food were approximately equal. Bottom: correlation between hypothetical selection of arms on the basis of food size (selection of Sizes 8 to 1 , sequentially) and actual performance. Note that acquisition was rapid under the sighted and the occluded conditions, and that food size did not influence the sequence of arm selections. 

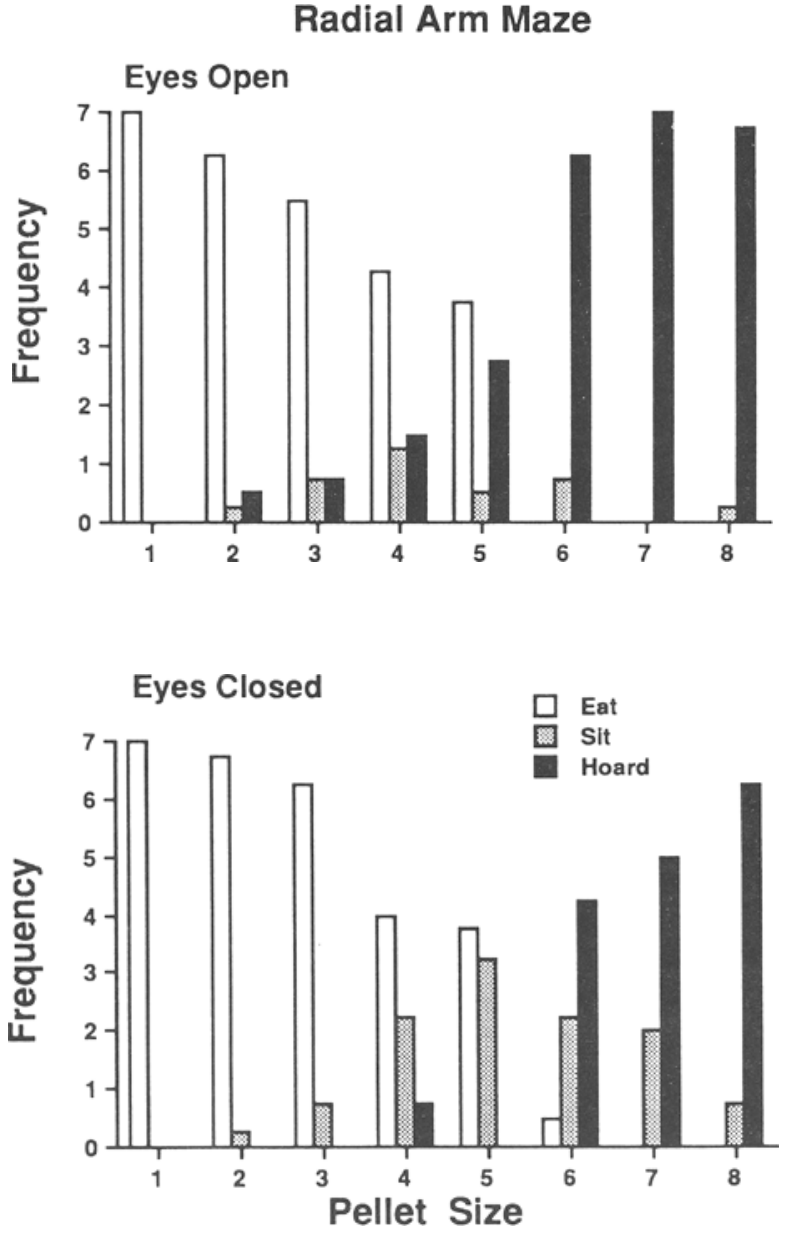

Figure 8. Effect of food-pellet size on behavior in an 8-arm radial maze. Each arm was baited with one pellet size, and the amount of food in each arm was equivalent. Note that as pellet size increased, behavior changed from swallowing ("eat") to sitting up and eating ("sit") to hoarding ("hoard"). Visual occlusion did not fundamentally modify motor responses, radial-arm maze acquisition, or pelletsize preference.

the end of the arms cautiously, but when they hoarded, they frequently galloped. When they reached the enclosure with a hoarded pellet, they sat back on their haunches, often performed one or two spontaneous dodges, and then ate the food. The incidence of sitting and eating on the arms was not high, but when it occurred, it was associated with the medium-sized food pellets (Figure 8). The overall analysis with eyes, pellet size, and motor behavior as main variables gave no significant main effects and only one significant interaction, pellet size $\times$ behavior $[F(14,42)$ $=16.54, p<.001]$.

\section{DISCUSSION}

This study makes two novel contributions to the understanding of food-defensive and food-hoarding behavior of the rat. First, the size of food pellets influences motor behavior in such a way that large food pellets are preferentially hoarded over smaller ones. If food pellets are very small, they are quickly swallowed, whereas if they are intermediate in size, they are consumed after the rat has adopted its typical sitting posture for feeding. Second, even if a rat does not have the opportunity to hoard, the size of food pellets influences behavior. As food-pellet size increases, the probability that a rat will dodge away from the food source with the food increases, as does the distance that it will dodge.

In his formative work on food hoarding in the rat, Bindra $(1948 a, 1948 b)$ suggests that rats hoard objects that they perceive as "valuable" (i.e., as related to some state of need). Calhoun's (1962) observations on wild rats in a seminatural environment expand upon this conclusion by pointing out that female rats will also hoard food to their nest for their litters, while all rats hoard food to "shucking stations" or shelters where it is either eaten or left. Here, we report that food size influences hoarding tendencies importantly. In light of previous work, our finding is both relevant and sensible. It is presumably more adaptive, in terms of energy conservation and risk, to hoard larger pieces of food rather than smaller pieces, as might also be suggested by optimal foraging theory (see Pyke, Pulliam, \& Charnov, 1977). Hoarding larger pieces of food might be adaptive in another way too. Bindra (1948b) and Viek and Miller (1944) have argued that rats transport food from areas of less security to areas of greater security. If a rat is at risk of losing food to a conspecific (Whishaw \& Tomie, 1987, 1988) or at risk of being attacked by predators, it would be useful for it to be able to "estimate" and reduce risk by hoarding large pieces of food.

We have been able to demonstrate that the relation between food size and hoarding tendencies is robust. First, unlike pigeons, which display individual differences in food choices (Shettleworth, 1987), all the rats that we have observed have displayed the same general relation between behavior and food size in a variety of conditions (eyes open or eyes occluded, food deprived or sated, foraging at short or at long distances from the home cage, or foraging in a simple covered straight alley or on an 8-arm maze with arms exposed). We suspect that there may be subtle relations between body size, exposure of the food source, etc., and responses to food size; nevertheless, we believe that the basic pattern of behavior that we describe here still prevails. Two previous studies have examined the effects of food size on choice preference in rats, but both have only indirect relevance. Yoshioka (1930) reported that in free choice tests, rats prefer to choose and eat large sunflower seeds rather than smaller seeds. Motor behavior and hoarding tendencies were not recorded. Smith, Maybee, and Maybee (1979) have reported that rats would select larger food pellets when foraging at more distant locations, but all of their food sizes were larger than the largest food pellets used here. We did not specifically examine these aspects of preference behavior.

In an attempt to account for hoarding behavior in terms of learning theory, Marx (1950) has argued that it is a habit formed primarily from the fusion of the earlier and independently learned "homing" and pellet-seizure 
habits. The major findings of the present study do not support this thesis. The nature of the rat's movement in response to food pellets of differing sizes appears to have the character of an innate species-typical action pattern (Hinde, 1982) or stereotyped behavior (Barnett, 1963). Furthermore, when the rats had the opportunity to select food pellets of different sizes on the 8-arm maze, there was no evidence that food size influenced choice. By contrast, if food is deleted from an arm or if the arm is baited with aversive or palatable substances, preferences do change quickly (Batson, Best, Phillips, Patel, \& Gilleland, 1986). That other factors, such as selection of the depot to deposit food, may be influenced by learning is not in dispute, although it is unlikely that learning is of the strict stimulus-response type (see Jones, 1986). Hoarding in the present study was resistant to visual occlusion in both the straight alley and the 8-arm maze. Furthermore, Tigner and Wallace (1972) have reported that blind rats hoard, and that anosmic rats hoard somewhat more than normal. These observations are inconsistent with a strict stimulus-response learning-theory account of hoarding. On the contrary, they suggest that rats may form a cognitive map (O'Keefe \& Nadel, 1978; Tolman, 1948) of their environment, which in turn directs hoarding. A particularly positive feature of such a central representational notion is that it predicts that hoarding behavior should be immune to dependence upon input from a single sensory system, as seems to be the case. Nevertheless, whatever representational features hoarding may eventually be found to have, this study demonstrates that food size is an important behavioral determinant.

When the destination was blocked off in order to eliminate hoarding, the rats made no attempt to hoard but they still made movements dependent upon food size. These involved seizing the food in the mouth and turning away from the food source before eating the larger food pellets. The distance that the rats moved and the angle that they turned increased as food size increased. These movements had the features of dodges, a previously described behavior of rats attempting to protect food from conspecific theft (Whishaw \& Tomie, 1987, 1988). In previous analyses of dodging behavior, we have noted that in response to persistent attacks from conspecifics, the distance that dodges carried the rat increased to the point at which a rat would complete a dodge by bounding away. Perhaps dodging is adaptive not only for escaping an attempted theft but in forming a nexus that under appropriate conditions leads to hoarding. Thus, dodging and hoarding not only would serve the common objective of anticipating and frustrating potential theft, but also would form a continuum, in that dodging could expand avoidance movement into the more complex action of hoarding.

In summary, in this paper we report a robust relationship between the motor behavior of rats and food-pellet size, in laboratory foraging paradigms. Foraging rats, on encountering food, swallow small pieces of food directly, sit up and eat medium-sized pellets, and hoard large pellets. The paradigm can provide a simple laboratorybased model for studying various aspects of food-related movements, including dodging and hoarding. There has been substantial interest in the neural basis of hoarding, but traditionally, studies have involved the use of large food pellets (Borker \& Gogate, 1980; Herberg \& Blundell, 1967; Kelley \& Stinus, 1985; Kolb, 1974; Kolb \& Whishaw, 1981; Stamm, 1954; Stinus, Gaffori, Simon, \& LeMoal, 1978; Wallace \& Tigner, 1972). The present paradigm could well provide an additional adjunct to this experimental approach.

\section{REFERENCES}

BARNeTt, S. A. (1963). The rat: A study in behavior. Chicago: University of Chicago Press.

Batson, J. D., Best, M. R., Phillits, D. L., Patel, H., \& Gilleland, K. R. (1986). Foraging on the radial-arm maze: Effects of altering the reward at a target location. Animal Learning \& Behavior, 14, 241-248.

BindRA, D. (1947). Water hoarding in rats. Journal of Comparative \& Physiological Psychology, 40, 149-156.

BiNDRA, D. (1948a). The nature of motivation for hoarding food. Joumal of Comparative \& Physiological Psychology, 41, 211-218.

BINDRA, D. (1948b). What makes rats hoard? Journal of Comparative \& Physiological Psychology, 41, 379-402.

Borker, A. S., \& Gogate, M. G. (1980). Hoarding in caudate lesioned rats. Indian Journal of Experimental Biology, 18, 690-692.

CAlmoun, J. B. (1962). The ecology and sociology of the Norway rat. (Public Health Service Publication No. 1008). Washington, DC: U.S. Government Printing Office.

COHEN, L., \& HolldDAY, M. (1982). Statistics for social scientists. London: Harper \& Row.

Fantino, M., \& Cabanac, M. (1980). Body weight regulation with a proportional hoarding response in the rat. Physiology \& Behavior, 24, 939-942.

Fantino, M., Cabanac, M. (1984). Effect of a cold ambient temperature on the rat's food hoarding behavior. Physiology \& Behavior, 32, $183-190$.

Herberg, L. J., \& Blundell, J. E. (1967). Lateral hypothalamus: Hoarding behavior elicited by electrical stimulation. Science, 155 , 349-350.

Herberg, L. J., Pye, J. G., \& Blundell, J. E. (1972). Sex differences in the hypothalamic regulation of food hoarding: Hormones versus calories. Animal Behavior, 20, 186-191.

HiNDE, R. A. (1982). Ethology. New York: Oxford University Press. JONES, C. H. (1986). Grammatical principles of the food hoarding behavior of the Syrian golden hamster (Mesocricetus auratus). Unpublished master's thesis, Dalhousie University, Halifax, Nova Scotia, Canada.

Kelley, A. E., \& Stinus, L. (1985). Disappearance of hoarding behavior after 6-hydroxydopamine lesions of the mesolimbic dopamine neurons and its reinstatement with 1-dopa. Behavioral Neuroscience, 99, 531-545.

KoLB, B. (1974). Prefrontal lesions alter eating and hoarding in rats. Physiology \& Behavior, 12, 507-511.

Kolb, B., \& Whishaw, I. Q. (1981). Neonatal frontal lesions in the rat: Sparing of learned but not species-typical behavior in the presence of reduced brain weight and cortical thickness. Journal of Comparative \& Physiological Psychology, 95, 863-879.

LickLider, L. C., \& LickLIDER, J. C. R. (1950). Observation on the hoarding behavior of rats. Journal of Comparative \& Physiological Psychology, 43, 129-134.

LORE, R. K., \& FlanNelly, K. (1978). Habitat selection and burrow construction by wild Rattus norvegicus in a landfill. Journal of Comparative \& Physiological Psychology, 92, 888-896.

MARX, M. (1950). A stimulus-response analysis of the hoarding habit in the rat. Psychological Review, 57, 80-94.

McCain, G., Garrett, B. L., Reed, C., Mead, G., \& Kuenstler, R. (1964). Effects of deprivation on hoarding of objects other than the deprived material. Animal Behaviour, 12, 409-415. 
McCleary, R. A., \& Morgan, C. T. (1946). Food hoarding in rats as a function of environmental temperature. Journal of Comparative Psychology, 39, 371-378.

Miller, G. A., \& Postman, L. (1946). Individual and group hoarding in rats. American Journal of Psychology, 59, 652-668.

Miller, G. A., \& VIEK, P. (1944). An analysis of the rat's response to unfamiliar aspects of the hoarding situation. Journal of Comparative Psychology, 37, 221-231.

Morgan, C. T., Stellar, E., \& Johnson, O. (1943). Food deprivation and hoarding in rats. Journal of Comparative Psychology, 35, 275-295.

MuNn, M. L. (1950). Handbook of psychological research on the rat. Boston: Houghton Mifflin.

O'KeEFE, J., \& NADEL, L. (1978). The hippocampus as a spatial map. Oxford, England: Oxford University Press.

Pisano, R. G., \& Storer, T. I. (1948). Burrows and feeding of the Norway rat. Journal of Mammalogy, 29, 374-383.

Porter, J. H., Webster, F. A., \& Licklider, J. C. R. (1950). The influence of age and food deprivation upon the hoarding behavior of rats. Journal of Comparative \& Physiological Psychology, 44, 300-309.

Pyke, G. H., Pulliam, H. N., \& Charnov, E. L. (1977). Optimal foraging: A selective review of theory and tests. Quarterly Review of Biology, 52, 137-154.

Ross, S., Smith, W. I., \& Nienstedt, C. W., JR. (1950). The hoarding of non-relevant material by the white rat. Journal of Comparative \& Physiological Psychology, 43, 217-225.

Ross, S., SmTth, W. I., \& WoEssner, B. L. (1955). Hoarding: An analysis of experiments and trends. Journal of General Psychology, 52, 307-326.

SHETTLEWORTH, S. J. (1987). Individual differences in choice of food items by pigeons. Behavioral Processes, 14, 305-318.

Smith, J. P., Maybee, J. S., \& MaYbee, F. M. (1979). The effects of increasing distance to food and deprivation level on food-hoarding behavior in Rattus norvegicus. Behavioral \& Neural Biology, 27, 302-318.

Southern, H. N., Watson, J. S., \& Chitty, D. (1946). Watching nocturnal animals by infra-red radiation. Journal of Animal Ecology, 15, 198-202

St AMm, J. S. (1954). Control of hoarding activity in rats by the median cerebral cortex. Journal of Comparative \& Physiological Psychology, 47, 21-27.

Stellar, E., \& Morgan, C. T. (1943). The roles of experience and deprivation in the onset of hoarding behavior in the rat. Journal of Comparative Psychology, 36, 47-55.

Stinus, A. J., Gaffori, O., Simon, H., \& LeMoal, M. (1978). Disappearance of hoarding and disorganization of eating behavior after ventral mesencephalic tegmentum lesions in rats. Journal of Comparative \& Physiological Psychology, 92, 289-296.

TAKahashi, L. K., \& Lore, R. K. (1980). Foraging and food hoarding of wild Rattus norvegicus in an urban environment. Behavioral \& Neural Biology, 29, 527-531.

Tigner, J. C., \& Wallace, R. J. (1972). Hoarding of food and nonfood items in blind, anosmic and intact albino rats. Physiology \& Behavior, 8, 943-948.

Tномpson, H. V. (1948). Studies of the behavior of the common brown rat. Bulletin of Animal Behaviour, 6, 26-40.

Tolman, E. C. (1948). Cognitive maps in rats and men. Psychological Review, 55, 189-209.

VIEK, P., \& Miller, G. A. (1944). The cage as a factor in hoarding. Journal of Comparative Psychology, 37, 203-210.

Wallace, R. J. (1974). Tail-hoarding in the albino rat. Animal Behavior, 24, 176-180.

Wallace, R. J. (1978). Hoarding of inedible objects by albino rats. Behavioral Biology, 23, 409-414.

WALLACE, R. J. (1979). Novelty and partibility as determinants of hoarding in the albino rat. Animal Learning \& Behavior, 7, 549-554.

Wallace, R. J. (1985). Object retrieval preferences of Norway rats: An evolutionary generalization of behavior. Experientia, 41, 1479-1482.

Wallace, R. J., \& Tigner, J. C. (1972). Effects of cortical and hippocampal lesions on hoarding behavior in the albino rat. Physiology \& Behavior, 8, 937-942.

Whishaw, I. Q., \& TomiE, J. (1987). Food wresting and dodging: Strategies used by rats (Rattus norvegicus) for obtaining and protecting food from conspecifics. Journal of Comparative Psychology, 101, 202-209.

Whishaw, I. Q., \& Tomie, J. (1988). Food wresting and dodging: A neuroethological test of cortical and dopaminergic contributions to sensorimotor behavior. Behavioral Neuroscience, 102, 110-123.

WOLFE, J. B. (1939). An exploratory study in food-storing in rats. Journal of Comparative Psychology, 28, 97-101.

YoshiokA, J. G. (1930). Size preference of albino rats. Joumal of Genetic Psychology, 37, 427-430.

(Manuscript received June 27, 1988; revision accepted for publication September 15, 1988.) 